\title{
Study on the Formation Mechanism of Intention to Experience B\&B Based on Grounded Theory
}

\author{
Du Jianwen ${ }^{1, ~ a ~, ~ C a o ~ M i n g c h u n ~}{ }^{2, ~ b}$ \\ ${ }^{1}$ School of Management, Chongqing University of Technology, Chongqing, 400054, China \\ ${ }^{2}$ School of Management, Chongqing University of Technology, Chongqing, 400054, China \\ a425905192@qq.com, ${ }^{b} 1162011704 @ q q . c o m$
}

Keywords: B\&B; intention to experience; Grounded Theory; formation mechanism

\begin{abstract}
Based on the textual data of 309 effective sentences from Blog, micro-blog and WeChat, using qualitative research methods, through Open Coding, Axial Coding and Selective Coding, the triple process of Grounded Theory to analyze, the study found the six core categories, namely formation factors that influence the tourists' intention to experience B\&B. The "story-line" shows the typical relationship structure between the categories, and then it builds a formation mechanism of intention to experience B\&B and shows the factors' roles in the framework of the model, while reflecting the conditions contained in the implementation of the context of each type of intention. The study finally explains that comfort and nostalgia are the two most important factors in promoting the intention to experience $\mathrm{B} \& \mathrm{~B}$, and from the perspective of tourists, explores that the $\mathrm{B} \& \mathrm{~B}$ should play the role of "soul" of the host in design and construction in the future.
\end{abstract}

\section{Introduction}

$\mathrm{B} \& \mathrm{~B}$ originated in Japan, issued in Taiwan, China. As the country is more "tolerant" to new things and people's minds are more open, "For A Bed, Go To A City", the B\&B has become the demand orientation for rural tourism.

As a special concept of accommodation, the development of B\&B is not only the development of the hostel, but the transformation of the rural development ${ }^{[1]}$. B\&B is an tourism reception facility that can give visitors "the feeling of home" and an important carrier to experience the life and culture among the tourist destination, which is different from the traditional hotel ${ }^{[2]}$. With the increasing prosperity of the tourist market and changes in tourism demands, the B\&B has evolved from a simple accommodation product to a new form of tourism -"Home Tourism". And the so-called "Home Tourism", is that people enjoy the slow life, into local life, with the help of home stay to engage tourist activities, early adopters and experience alternative travel ${ }^{[3]}$. However, this emerging thing is facing serious risks about planning and design homogeneity, construction-operation homogeneity; and many places reduce their threshold which lead to a blowout development of $B \& B^{[4][5][6]}$. With the fall of a large number of $B \& B$ projects, a new supply imbalance of the $B \& B$ products or will appear in the feature.

Visitors' intention of the use of tourism is an important way for the accurate development of $B \& B$. Analyzing and mastering the visitors' intention to experience $B \& B$, exploring how to run the 
hostel better not only can improve the effectiveness of planning, design, construction and operation to achieve sustainable development, but also can provide marketing support for traditional villages and towns to raise the rural tourism Heat by using their residential tourism resources. While at present, there has not yet found the study on visitors' intention to experience B\&B neither at home and abroad.

In order to accurately find out the formation mechanism of visitors' intention to experience B\&B and help it to locate the direction of design and operation from the perspective of tourist market, this paper uses the Grounded Theory research paradigm to summarize, abstract and refine the visitors' corpus about $\mathrm{B} \& \mathrm{~B}$, then to analyze the constituent factors that make up the mechanism of intention to experience $B \& B$ and their action ways. So as to further study on visitors' psychological demands and $\mathrm{B} \& \mathrm{~B}$ planning to guide the planning of home tourism, constructing and designing in the rural tourism development.

\section{Literature Review}

\subsection{Consumer Characteristics of B\&B}

Accompanied by china's domestic tourism showing the trend of FIT and In-depth travel, the amount of B\&B market soared and the consumers in the consumption of this product show some obvious features.

First, from the characteristics of consumer structure, the characteristics of consumers for mainly for the level of education and income levels are relatively high, there are more leisure time and family travel needs, and a higher consumption capacity for trips ${ }^{[7]}$. Among them, in the survey of Hongkong tourists on their preference of $\mathrm{B} \& \mathrm{~B}$, it found that young, accepted the higher education and middle -income women are the mainland's main market groups ${ }^{[8]}$; and in the survey of tourists in Taiwan, it found that visitors who will choose a B\&B show the features of the core family, access to a good education, and middle-low classes ${ }^{[9]}$. These consumers show a obvious features in demands and consumption capacity will be long-term supports for a continued development of Chinese B\&B.

Then, from the consumption patterns of the market, the consumption of modern tourists has presented from the past which focused on the consumption on the value of use to the consumption on symbol and symbolic meanings ${ }^{[10]}$, and people is very sensitive to the B\&B's "home" atmosphere $^{[11]}$. Gunasekaran N.and V. Anandkumar found in their study of tourists in Pondicherry of India that "home like", "native culture" are the main factors influencing the visitors to choose $\mathrm{B} \& \mathrm{~B}$ or not $^{[12]}$. When it comes to $\mathrm{B} \& \mathrm{~B}$, visitors not only want to enjoy a comfortable living environment, a variety of service equipment ${ }^{[13]}$, but also enjoy the "host-guest relationship" will bring an emotional dependence under some artificial environment ${ }^{[14]}$, which confirms the changes in the forms of tourists' consumption, and in order to achieve a rapid development, advancing with the times, we must fully understand the tourists' psychological need and consumer demand, then make a explicit supply.

\subsection{Tourism Experience Motivation}

The process of tourists' travel to non-normal environment for the experiences of resources, activities is actually a behavioral process of searching for self-nature with human nature alienation $^{[15]}$. Through the empathy process of being influenced by the education and nature, escaping the reality, enjoying the beauty of the landscape-environment, entertaining atmosphere and releasing feelings, so that to achieve the functions with knowledge education, relaxation of escaping, novelty aesthetics, entertainment and empathy ${ }^{[16][17]}$, and access to self-existence value and status, 
escape the reality of pressures, leisurely entertainment and baptism of historical and cultural memory ${ }^{[18]}$. The core of the tourism is the practical experience, experienced transformation, emotion and cultural knowledge ${ }^{[19]}$, and its style including culture, folklore, festivals, ethnic customs, nature, learning, life, living, adventure, recreational activities, feelings, dreams and so on $^{[20]}$. All the real state and behaviors, tourists show in the experience, reflect their hopes that through the type of experience to adjust the purpose of life under a non-normal environment ${ }^{[21][22]}$. But its quality is closely linked with the level of experience ${ }^{[23]}$, and depends on visitors' own knowledge, experience ,and their physical and psychological state during the tour ${ }^{[24]}$,and finally form different levels of quality and satisfaction between different visitors, rom the sensory organs to the emotion, cognition, regression, the soul ${ }^{[25]}$. Gilbert, etc. also through the study confirmed that tourism and leisure experience in a positive state can produce positive emotions, the happiness is higher than the non-tourism people in the same state ${ }^{[26]}$.

The experience is the soul of the bed and breakfast, the gap in the quality of the room, the different lifestyles based on the price, the choice of location, the space creation, the landlords' characteristics and the brand management of $B \& B$, will affect the visitors' perception of the experience and their loyalty to the $B \& B^{[27]}$. In view of the study of $B \& B$, some scholars believe that the tourists' perception on the experience to a large extent from emotional authenticity perception and emotional expression, the emotional factor is the key that lead tourists to form the intention to experience $B \& B$ and whether they will praise finally ${ }^{[28]}$. In the exploration of the sense of home tourism, someone think that the authenticity of culture is the crucial factor during the experience $\mathrm{B} \& \mathrm{~B}$ to visitors. So, they put forward that from these aspects like highlighting the cultural authenticity in design, improving the cultural quality of operators, creating a cultural scene atmosphere to enhance tourists' cultural expectation and real awareness and strengthen the satisfaction and the probability of re-crossing ${ }^{[29]}$.

\subsection{Influencing Factors of Tourism Intention}

Intentional motivation is the cause of behavior, is the driving force to promote the behavior to react $^{[30]}$, and it affects the direction and intensity of specific behaviors $31^{[}$. The image perception of tourist destination is an important factor that influences the decision when people choose where to trave $^{[32][33]}$. The image of the destination will have a significant impact on the travel behaviors of tourists at all stages of the tour, including before, during and after the tour ${ }^{[34]}$. First of all, the image of the tourist destination affects whether the potential tourists will have a trip and decide where to travel, affecting tourists' intention on a certain way to visit a certain place ${ }^{[35]}$; the better the perception of image or the value of the destination, the higher the tourist' intentions and the preference and the more likely the place to be the tourist destination ${ }^{[36]}$. Second, the destination's image will affect the tourist's travel satisfaction, what the visitors' evaluation to their own experience will affect the behavior after the tour, like the intention to re-visit, recommended intention and positive reputation, thus affecting the surrounding people's intention to travel the $\operatorname{spot}^{[37][38]}$.

In some specialized studies on rural tourism, they believe that distinctive areas will significantly improve the tourists' interest, tourists who leave the normal environment to travel to other destinations mainly attracted by there different local tourism resources and human environment ${ }^{[39][40]}$,the characteristics of the production style and the lifestyle of B\&B itself are the most attractive to tourists ${ }^{[41]}$. Tourism destination's price, location, rural customs, operators are heterogeneous resources, services and rural customs are the main source of competitive advantage in rural tourism, tourists' intention to choose the site of place is higher ${ }^{[42]}$,and the level of the popularity of the scenic spot will be in a very high level of $40 \%$ affect the choice of tourists' 
intention $^{[43]}$. LI Zhong-bin studies the characteristic villages in Wuling Mountain area and points out that the differentiated and diversified special industries are the supporting forces for the sustainable development of rural tourism, and he proposes a series of ideas-"B\&B + " for construction and development, such as the "B\&B" + natural ecology, "B\&B" + folk customs, "B\&B" + health pension ${ }^{[44]}$. However, it has also been found that the probability of willingness people choosing the land is positively related to the degree of the perfection of the tourism infrastructure. The scenic spot with relatively perfect infrastructure and can provide visitors with comfortable and convenient travel services will be more likely to attract visitors to ${ }^{[45]}$. In Taiwan,f or example, the high value-added, diversified, highly innovative and low-cost services advocated by Taiwan Minshuku are the keys to making Taiwan's Minshuku an influential international brand and attracting tourists from all over the world ${ }^{[46][47]}$, and then the format industrialization, product specialization, legalization of supervision, organizational autonomy, professionalization of talents and equilibrium in development in the field of B\&B industry, to form a unique experience perception and desire to this type of $B \& B^{[48]}$.

Based on the reading and summary of the relevant ,it is found that there are many researches by Chinese and foreign researchers on tourism including tourism experience motivation, tourist market and consumer characteristics, and have basically reached agreement on the research results. Besides some scholars research the business model and development management of Taiwan Minshuku in detail, the studies directly on B\&B just focus on the consumer characteristics temporarily, which analyzed the consumers' structural features and consumption patterns. And regarding the home tourism as one of ways of travel to study the influencing factors of tourists' intention to experience $B \& B$. The study on how does the intention to experience $B \& B$ form, what is the formation mechanism of intention to experience $B \& B$ and under this kind of mechanism what are the contextual conditions to implement tourists' actions to experience B\&B is still lacked or even blank. Thus, this paper that focus on the formation mechanism of visitors' intention to experience B\&B is an important supplement in the filed of B\&B and tourism.

\section{Research Design and Method}

\subsection{Data Acquisition and Analysis}

Grounded Theory is a very important qualitative research method, based on the empirical data, through the step-by-step coding and analysis to construct a theory from bottom up ${ }^{[49]}$. The most critical of Grounded Theory is conceptualization and categorization, and the process of categorization includes three steps: Open Coding, Axial Coding and selective Coding.

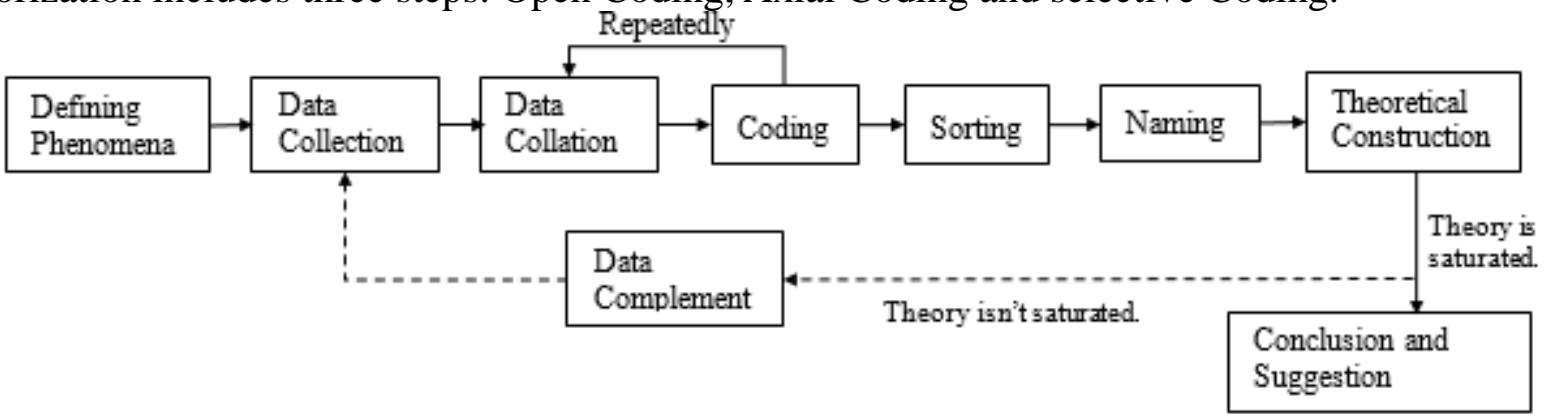

Fig1. General process of Grounded Theory

In the way to share the feelings of travel, blog, micro-blog and We-Chat has become the most popular choice. Therefore, as shown in Figure 1,through the blog, micro-blog, We-Chat and other open sources of information, this paper access to tourists' 327 statement text on the B\&B 
experience first, after extracting and sorting the relevant statements and images with $\mathrm{B} \& \mathrm{~B}$, removing the text that cannot be conception-recognized, and then obtaining the valid statement 309, analyzing the data text, combing the extraction and concept and coding elements, through the progressive(three level)coding for the qualitative analysis to complete the theoretical construction.

\subsection{Analysis Process}

\subsubsection{Open Coding}

Open Coding is the process by which the researcher decomposes the information obtained, compares, extracts the conceptual label, and then integrates the refining category to reflect the content of the data ${ }^{[50]}$. In the process of coding, we completely follow the words of the 309 obtained text, analyze literally to conceptualize, and through the words to reflect the categories of tourists' intention to experience what is more complicated, and final in this process of open coding, compress and extract " near the attractions or scenic spots", "good natural environment", "value for money", "escaping from stress or trouble”, "safety first”, "cost-effective”, "considerate service”, "room with style or theme or no" and so on 103 categories which encoding OC-1,OC-2 to OC-103 in order, as shown in table 1.

Tab. 1 Analysis of open coding (part of examples)

\begin{tabular}{|c|c|c|c|}
\hline Coding & Categorization & Conceptualization & Statement Text \\
\hline OC-1 & $\begin{array}{l}\text { near the } \\
\text { attractions or } \\
\text { scenic spots }\end{array}$ & near Myeong-dong & Who can introduce a reliable B\&B or hotel near Myeong-Dong ? \\
\hline OC-2 & value for money & unexpected surprise & We rented a B\&B which is actually a luxury villa when we arrived. \\
\hline OC -3 & escaping from & escape from the rain & $\begin{array}{l}\text { Birthday, take a bus to buy a cake then to B\&B, escape from the rain in } \\
\text { Taipei. }\end{array}$ \\
\hline & stress or trouble & shed our skin & $\begin{array}{l}\text { Qingjing B\&B,go to walk around the mountain under the warm } \\
\text { sun,despite the troubles and shed our skin. }\end{array}$ \\
\hline OC-4 & cost-effective & high cost performance & $\begin{array}{l}\text { Selected carefully a favorite Chengdu B\&B From a lot of dazzling } \\
\text { B\&B in the list, high cost performance and comfort coexist, buddies } \\
\text { for reference! }\end{array}$ \\
\hline OC-5 & $\begin{array}{l}\text { Convenient } \\
\text { transportation }\end{array}$ & $\begin{array}{l}\text { convenient to go } \\
\text { anywhere }\end{array}$ & $\begin{array}{l}\text { Osaka B\&B,people going to Osaka don't miss it,it is in the city center } \\
\text { and and convenient to go anywhere. }\end{array}$ \\
\hline \multirow{2}{*}{ OC-6 } & \multirow{2}{*}{ safety first } & $\begin{array}{l}\text { safety is the most } \\
\text { important }\end{array}$ & $\begin{array}{l}\text { B\&B is good or not is Second, the most important thing is safety, do } \\
\text { not live one night by the fire, or do not know how to die. }\end{array}$ \\
\hline & & $\begin{array}{l}\text { occurrence of home theft } \\
\text { cases }\end{array}$ & $\begin{array}{l}\text { There occurred a home theft case in Lutz village of Tonglu's B\&B } \\
\text { street,i will not to go there anymore. }\end{array}$ \\
\hline OC-7 & $\begin{array}{l}\text { considerate } \\
\text { service }\end{array}$ & reception is quite good & $\begin{array}{l}\text { This time did not live in the hotel,but choose a B\&B,the reception is } \\
\text { quite good,so happy! ah ha ha. } \\
\text { This is the best experience in B\&B so far. The boss is very } \\
\text { enthusiastic,he ran a few times in order to solve the problem of register } \\
\text { the especially, it is not so peace of mind in my own city. }\end{array}$ \\
\hline OC-8 & $\begin{array}{l}\text { good natural } \\
\text { environment }\end{array}$ & $\begin{array}{l}\text { everywhere is the } \\
\text { scenery }\end{array}$ & $\begin{array}{l}\text { To promote a fresh and refined B\&B,everywhere is the scenery to } \\
\text { photo }\end{array}$ \\
\hline ....... & ....... & ....... & ....... \\
\hline OC-103 & $\begin{array}{l}\text { room with style } \\
\text { or theme or no }\end{array}$ & $\begin{array}{l}\text { cool theme of "Lost in } \\
\text { space" }\end{array}$ & $\begin{array}{l}\text { A B\&B with the cool theme of "Lost in space" of the version of the } \\
\text { TOS in Russia! So cool! }\end{array}$ \\
\hline
\end{tabular}

\subsubsection{Axial Coding}

Axial Coding is the process of comparing the results of open coding constantly, distinguishing 
and clustering the secondary category and refining the main category to make it more logical and theoretical $^{[51] \text {. }}$ Based on the open coding,trough the axial coding summing up the small category at the micro-level(categorization 1), and then the micro-category is refined to form the results of axial coding(categorization 2).

The process is shown in table 2,we summed up including "geographical location", "natural environment", "architectural style" and other 20 categories at the micro-level for the first time, the classification is still more complex; therefore, analogy with the micro-categories continuously and dig out the 8 main categories at the macro-level finally, including location and environmental issues(AC-1), comfort(AC-2), security issues(AC-3), nostalgia(AC-4), social connections(AC-5), price and value(AC-6), brand(AC-7), innkeepers’ personal charm(AC-8).

Tab.2 Analysis of axial coding

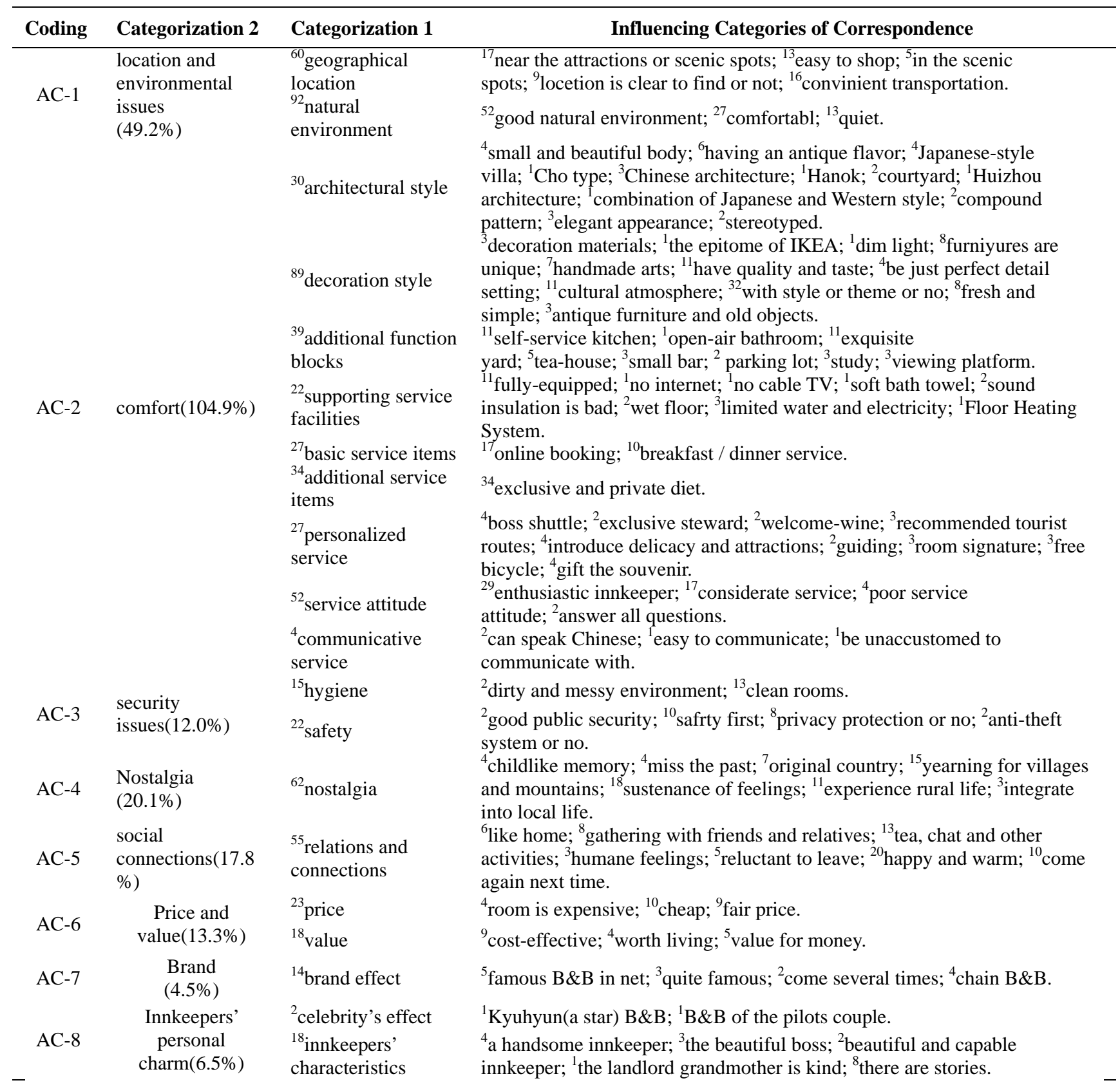

Note: Figures in the upper left corner indicate the frequency of each category being reflected in the all 309 valid statements; 
The percentage below the text indicates the percentage of the total frequency of the category in all 309 valid statements.

\subsubsection{Selective Coding}

Selective Coding is the process of digging out the core categories on the basis of the knowledge of the previous two coding categories, analyzing and summarizing the links between the core categories and other categories, and organically forming the theory ${ }^{[52]}$. Based on the relationship between the categories of axial coding, the concept are reestablished in this process again,the "location and environmental issues" and "comfort" are unified as the "comfort", the "price and value" and "brand" are unified as the "value",to sort out 6 core categories,namely the discovery about the contributing factors of tourists' intention to experience B\&B,respectively,the "nostalgia",the "social connections" at the individual level and the "comfort",the "safety" ,the "value" and the "innkeepers' personal charm" at the B\&B level; and depict a "story-line" to describe the typical relational structure between the categories as shown in table 3.

Tab.3 Category Typical Relational Structure (Story-line)

\begin{tabular}{|c|c|c|}
\hline Visitors' representative statement text & $\begin{array}{l}\text { Connotation of } \\
\text { relational structure }\end{array}$ & $\begin{array}{l}\text { Typical Relational } \\
\text { Structure }\end{array}$ \\
\hline $\begin{array}{l}\text { This is a B\&B hidden in the Ling'an Shenlongchuan scenic } \\
\text { area in Sichuan province. It's gentle and natural and the } \\
\text { autumn is also picturesque here! Because relying on the rich } \\
\text { resources of scenic spots, so it has a very hot smoke daily, } \\
\text { life is too comfortable and too rich! }\end{array}$ & $\begin{array}{l}\text { The perceived inducement of geographical } \\
\text { location and environment of B\&B is the } \\
\text { important clue for tourists who care the } \\
\text { "comfort" to form intention to B\&B. }\end{array}$ & $\begin{array}{l}\text { Łlocation and } \\
\text { environmental issues } \\
\quad(\text { COMFORT })\end{array}$ \\
\hline $\begin{array}{l}\text { In Mexico,living in a characteristic B\&B with chance,the } \\
\text { innkeeper gave me a small attic with a sense of design. } \\
\text { Waking up in the morning with sun on the pillow,it’s warm } \\
\text { and comfortable like home and i don’t want to leave. Come } \\
\text { again next time! }\end{array}$ & $\begin{array}{l}\text { The perceived inducement of the } \\
\text { comfortable facilities of B\&B is the } \\
\text { important clue for tourists who care the } \\
\text { "comfort" to form intention to B\&B. }\end{array}$ & $\begin{array}{c}\leftarrow \text { Comfort } \\
(\text { COMFORT) }\end{array}$ \\
\hline $\begin{array}{l}\text { There occurred a home theft case in Lutz village of Tonglu's } \\
\text { B\&B street,i will not to go there anymore. }\end{array}$ & $\begin{array}{l}\text { The perceived inducement of the security } \\
\text { protection system of B\&B is the important } \\
\text { clue for tourists who think the"safety first" } \\
\text { to form intention to B\&B. }\end{array}$ & $\begin{array}{l}\leftarrow \text { Safety issues } \\
\quad \text { (SAFETY) }\end{array}$ \\
\hline $\begin{array}{l}\text { For a long time i was not awakened by the rhythm of the } \\
\text { rain, no thunder and lightning, the gentle rain along the } \\
\text { eaves fell to the ground. Living in such a good } \\
\text { B\&B,listening to such a rain,as if back to my hometown for } \\
\text { he summer holiday as a child;this feeling is both familiar } \\
\text { and unfamiliar,oh,time never go back. }\end{array}$ & $\begin{array}{l}\text { The perceived inducement of the factors } \\
\text { about the expression of nostalgia of B\&B is } \\
\text { the important clue for tourists who have the } \\
\text { inner feeling of "nostalgia"to form intention } \\
\text { to B\&B. }\end{array}$ & $\begin{array}{c}\leftarrow \text { Nostalgia } \\
\text { (NOSTALGIA) }\end{array}$ \\
\hline $\begin{array}{l}\text { Signing on a sunny beach,the B\&B we live in is the rented } \\
\text { from their house by a pair of old couples. Here it is so } \\
\text { special to us to live with foreigners completely,we have } \\
\text { coffee,chat together in the evening and l change the We-Chat } \\
\text { with a handsome boy;the people is enthusiasm to burst. The } \\
\text { world is very big, we can not stop to go. }\end{array}$ & $\begin{array}{l}\text { The perceived inducement of the chance to } \\
\text { have relations and connections of B\&B is } \\
\text { the important clue for tourists who care the } \\
\text { "social connections"to form intention to } \\
\text { B\&B. }\end{array}$ & $\begin{array}{l}\leftarrow \text { relations and } \\
\text { connections } \\
\text { (SOCIA } \\
\text { CONNECTIONS) }\end{array}$ \\
\hline $\begin{array}{l}\text { We did not choose an expensive holiday hotel for this trip, } \\
\text { but booked a local B\&B online. Besides the advantages of } \\
\text { price,one of its characters is very attractive to me- i can } \\
\text { directly understand the local culture. }\end{array}$ & $\begin{array}{l}\text { The perceived inducement of the fair price } \\
\text { and value of B\&B is the important clue for } \\
\text { tourists who care it's "value"to form } \\
\text { intention to B\&B. }\end{array}$ & $\begin{array}{l}\leftarrow \text { price and value } \\
\quad \text { (VALUE) }\end{array}$ \\
\hline $\begin{array}{l}\text { The first time in Korea ,i want to live in the Kyuhyun(a star) } \\
\text { B\&B which has been full of rooms yesterday and we can't } \\
\text { find a accommodation. But,,we wait in the line to book for a } \\
\text { long time today,finally come to the B\&B. }\end{array}$ & $\begin{array}{l}\text { The perceived inducement of the innkeepers' } \\
\text { characteristics of B\&B is the important clue } \\
\text { for tourists who care the "innkeepers' } \\
\text { personal charm”to form intention to B\&B. }\end{array}$ & $\begin{array}{l}\leftarrow \text { innkeepers’ } \\
\text { characters } \\
\text { (INNKEEPERS’ } \\
\text { PERSONAL } \\
\text { CHARM) }\end{array}$ \\
\hline
\end{tabular}

\subsection{Formation Mechanism of Intention to Experience B\&B}

Based on the typical relational structure between the categories in Table 3, it has been possible to 
determine the way in which the factors influencing visitors to form a intention to experience B\&B. On this basis,this paper build the formation-mechanism model of visitors' intention to experience $\mathrm{B} \& \mathrm{~B}$ and the theoretical framework of the influencing factors' action way,and at the same time reflect the contextual conditions when tourist is in forming and executing his intentional behavior,as shown in Figure 2.

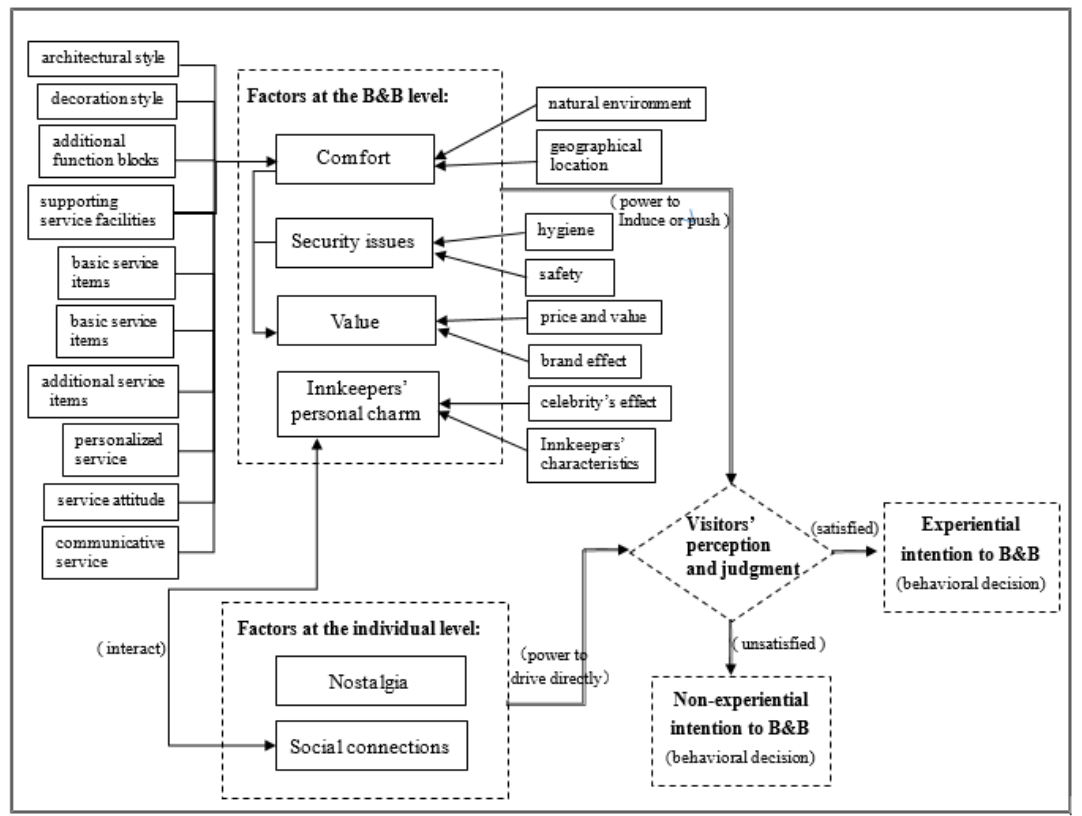

Figure 2. Formation Mechanism (pathway) of tourists’ intention to experience B\&B

\section{Research Conclusions and Discussion}

To some extent, experiencing B\&B is completely the subjective behavior of the crowd, but tourists in the process of decision-making of this behavior, not only affected by the their inner perception and needs, but also by the outside world like tourism destination and tourism. The formation of the intention to $B \& B$ is influenced by the factors at double levels of tourists themselves and $\mathrm{B} \& \mathrm{~B}$; the formation mechanism of intention under the influences of factors is controlled by the driving force and induced force of pushing force to carry out the two bidirectional control, “driving-pulling” or "driving-pushing”, and ultimately by the tourists judging the objective and subjective conditions to make a certain decision to B\&B. The tourist level includes nostalgia and social connections, which tend to play a positive role in the formation mechanism of intention, pushing the tourists to the B\&B. The objective factors at B\&B level like innkeepers' characteristics, degree of comfort, safety and value have both positive and negative effects on the formation mechanism of intention, so that the factors at $B \& B$ become the references of whether or not the tourists decide to achieve the intentional behaviors.

\subsection{At the Individual Level: The Tourists Themselves Nostalgia and Social Connections Directly Drive the Formation of Visitors' Intention to Experience B\&B}

Intention is actually a tendency like desire, strategy shown in the time when people behave in a way that deal with or treat an objective problem ${ }^{[53]}$. The nostalgia in the heart will directly drive visitors to experience the $B \& B$ to meet the desire of expressing the inner inner feelings; social connections are the tools or means for people to constantly enrich themselves, expand themselves and develop themselves. Often a good social networking platform provide by the $B \& B$ can be a 
direct drive to people to experience the $\mathrm{B} \& \mathrm{~B}$, and this power will closely be associated with and interact with the individual charm and effect of innkeepers. There is a desire to behave, therefore, the desire to express the nostalgia and develop social connections is the first direct guide for visitors to execute the behaviors of experiencing $\mathrm{B} \& \mathrm{~B}$.

\subsection{At the B\&B Level: The Objective Conditions of B\&B and Innkeepers' Charm Indirectly Induce or Push The formation of Visitors' Intention to Experience B\&B}

Whether visitors will have the desire or idea to choose a B\&B to experience, not only from the release of inner emotion and the individual needs, but also take in account the objective conditions of B\&B that can or cannot meet the visitors' own requirements and expectations.

For tourists, the objective conditions at the B\&B level including the "comfortable or not", "safe or not", "meeting the expectation of value or not" and "the innkeepers' performance is satisfactory or not " that will indirectly induce or push visitors' experiential behavior when this desire has been formed but is not sufficient to enable visitors to act directly. It is means that the factors at the B\&B level will affect the answer to the question of whether visitors choose a B\&B to accomplish the style of experience when the body has produced a desire but he still can't make a decisive response; if these objective conditions and son on have been able to meet the expectations and requirements, and reach the degree of satisfaction, then visitors will implement to experience the $\mathrm{B} \& \mathrm{~B}$; on the contrary, will not.

Based on the analysis of grounded theory, the data analysis shows the six major factors that affect the formation of tourists' intention to $B \& B$, and there are 20 influencing factors at the micro-level (that is, the result of categorization at the micro level in the axial coding.) and 8 influencing factors at the macro-level (that is, the main category at macro level.) that affect visitors to behave to react the existing intention. We use the percentage of the factors' frequency reflected in all 309 valid statements as the weight of the evaluation index, namely, the degree of influence of different factor, which reflect the tourists' concerns when it is ready to perform the intention to $\mathrm{B} \& \mathrm{~B}$, as shown in table 2 .

The first, $\mathrm{B} \& \mathrm{~B}$ as a special concept of accommodation, comfort is still the most concerned issue of tourists, and the material entity that affect the degree of comfort is still the core in design and construction of B\&B. In all 309 valid statements, the category about the meanings of "comfort" appears 476 times repeatedly, about $154 \%$, which means there will be retrieved to mention the comfort of B\&B in each statement text. In the macroscopic influencing factors, the weights of the first and second factors are geographical location and comfort, accounting for $49.2 \%$ and $104.9 \%$ respectively, and architectural design, facilities and other functional blocks are more mentioned in the factors that can affect the comfort, these are the categories of material entity. It confirm that people will choose the experience to $\mathrm{B} \& \mathrm{~B}$ or not, will implement to achieve the intention to $\mathrm{B} \& \mathrm{~B}$ or not, the degree of the comfortable issues of $B \& B$ play an important roles, and it is important for guiding the $\mathrm{B} \& \mathrm{~B}$ to locate, design, construct.

The second, consumers actions for this type of tourism products-B\&B tend to be emotional and experiential consumption-seeking the expression of the inner nostalgia. The words like "childlike", "memory", "rural villages and mountains" and "nostalgia" mentioned in the statement text account for a large number of $20.1 \%$,the weight rank third and reflects the reason why tourists choose a $\mathrm{B} \& \mathrm{~B}$ is from the expression of the inner feelings and is the wake of memory and emotional involvement by the B\&B. It verifies that the "nostalgia" is lifeline which can't be given up of Chinese, and the "nostalgia" will become a eternal topic and guide the constructions of countrysides.

The last, B\&B itself is just the materialized present of innkeepers’ lifestyles, the consumption of 
B\&B tend to chase the innkeepers' charm. Ten thousand tourists there are ten thousand kinds of $\mathrm{B} \& \mathrm{~B}$ in the minds, in fact, the real meaning of a $\mathrm{B} \& \mathrm{~B}$ is only a lifestyle for the innkeepers and tourists. In the statement text, there are many times to mention the words of "there are stories”, “a handsome innkeeper", "the beautiful boss" and so on, tourists' love to the innkeepers' charm is actually the yearning for the life prototype behind them. Therefore, the concept of B\&B will no longer be a room or its function, it should play the "soul" of the innkeeper, basing on the basic services, build a scene or a story around the innkeeper to achieve "personalized".

\section{Research Limitation and Prospect}

By using qualitative analysis method, based on the step-by-step analysis of Grounded Theory, this paper attempts to explore and identify the factors that affect the formation of tourists' intention to experience $B \& B$, construct the model of mechanism of the formation mechanism of intention. The results of the research can further stimulate the study of the tourists' perception on the B\&B in the background of tourism development, and can also be a reference and guide for the planning, development and design of the tourist attractions or villages.

As an exploratory research, there are some limitations. First of all, restricted by objective conditions, this study bases on blog, micro-blog, We-Chat and other open data sources, due to the lack of verification, the conclusions about the formation mechanism of intention to $B \& B$ and the context conditions to implement the intentional behaviors whether are universal or not need to be verified in real life and the real tourism environment continuously, it needs further study. Secondly, there are still many controversies on the empirical researches and application of the qualitative research in the academic circle so far $^{[54]}$, the features of qualitative research method of this paper also causes some limitations, such as grounded theory, one of the qualitative research methods, because there is no preset, quantifiable-operation indicators, it more dependents on the subjective judgment of the researchers in the analysis process, so the reliability of its results is often tested.

In the future, study can be further based on the the survey of tourists in the real environment to compose the factor condition and the intention-relation scale, combine with computer simulation and other empirical methods to explore the cue characteristics of formation of tourists and regular pattern of its implement, to verify and supplement the practicality of the preliminary exploration results by grounded theory.

\section{References}

[1] Make home stay our tourism cornerstone [N]. Post-Courier (Papua New Guinea), 2004, (12):2-74.

[2] JIANG Zhizhou. Bed and breakfast travel short board and dilemma [J]. Quality and Standardization, 2016, (04):9-10.

[3] ZONG He. The global travel to B \&B industry is in the ascendant [N]. WWW.zgswcn.com, 2016-06-13, (12).

[4] WANG Yan. Thoughts on The Economic Development of the B\&B [J]. Shangqing, 2016,(51).

[5] QI Chunjiao,XU Qiaoling. Study on Hangzhou's Deep Tour Mode Based on Personalized Tourism [J]. Tourism Overview, 2016(04):130.

[6] LIU Yanhua. B\&B in this business [J]. XIAOKANG, 2016(6):40-42.

[7] JIANG Jiaqian, LI Yan. A review of the international and domestic researches on Minshuku[J]. Tourism Research, 2014,6(4): 16-22.

[8] JONES D, GUAN J J. Bed and Breakfast Lodging Development in Mainland China: Who is the Potential Customer?[J]. Asia Pacific Journal of Tourism Research, 2011, 16 (5): 517- 536.

[9] CHEN L, LIN S, KUO C. Rural tourism: Marketing strategies for the bed and breakfast industry in Taiwan [J]. International Journal of Hospitality Management, 2013 (3):278-286.

[10] HUANG Qixin,ZHOU xiao. Research on the Development Model of Rural B\&B Based on Cultural Authenticity [J]. Rural Economy and Science-Technology, 2012, (12):68-69.

[11] HU Rui. Chongqing B\&B-A new way of tourism, tourists to a "home” [J]. THE WORLD\&CHONGQING, 2016, (09):46-47. 
[12] GUNASEKARAN N, ANANDKUMAR V. Factors of Influence in Choosing Alternative Accommodation: A Study with Reference to Pondicherry, A Coastal Heritage Town [J]. Procedia-Social and Behavioral Sciences, 2012, (6):11271132.

[13] SUN Huangzhen, XU Yishan, XIAO Fangli. Study on the Satisfaction of Wuyi Mountain Based on Customer's Needs[J]. Journal of Anyang,Normal University,2016,(5):120-125.

[14] STRINGER P F. Hosts and guests the bed-and-breakfast phenomenon [J]. Annals of Tourism Research, 1981, 8(3):357-376.

[15] WANG Yongqi, A Wangcanjia. A Brief Analysis of the Deep Tourism Experience of Tibetan Buddhism Culture in Lhasa-A Perspective of Human Essence Alienation [J]. Economic Research Guide, 2013,(2):280-281.

[16] ZOU Tongqian,WU Liyun. The Essence, Types and Principles of Tourism Experience [J]. Tourism Science, 2003,(4): 7-10.

[17] SONG Yongmei,SUN Gennian. On the Theoretical Framework and Model of Experiential Tourism [J]. Social Scientist, 2006,(6):115-119.

[18] Sheng C W,Chen M C. Tourist experience expectations: Questionnaire development and text narrative analysis[J]. Tourism and Hospitality Research, 2013, 7(1): 93-104.

[19] LI Xiaoqin Tourism Experience Factors and Foundation of Dynamic Model [J].Journal of Guilin Institute of Tourism, 2006, 17(3):609-611.

[20] DOU Qing. On Tourism Experience [D]. Nan Ning: Guangxi University, 2003:23-26.

[21] WANG Xin,ZOU Tongqian. On the Significance of Experience under Unusual Environment [J]. Tourism Tribune, 2011,26 (07) :19-23.

[22] LI XiNjian. Study on Tourism Experience:Progress and Pondering[J]. Tourism Tribune, 2008,23(6):90-95.

[23] Agapito D, Mendes J, Valle P. Exploring the conceptualization of the sensory dimension of tourist experiences [J]. Journal of Destination Marketing \& Management, 2013,(2): 62-73.

[24] Anderson T D. The tourist in the experience economy [J]. Scandinavian Journal of Hospitality and Tourism,2007,7(1):46-58.

[25] LONG Jiangzhi,LU Changchong. The Hierarchy Model of Tourism Experience: Based on the Spectrum of Consciousness [J]. Journal of Beijing International Studies University,2009,(11): 9-19.

[26] Gilbert D, Abdullan J. Holiday taking and the Sense of Well-being[J]. Annals of Tourism Research, 2003,30(6):103-121.

[27] LI Yanqin,YU Wenhao,BAI Yufan. Comparative Research On B\&B Beijing and Taipei Based on Ratings on the Airbnb Website[J]. Chinese Journal of Management,2017,14(1):122-128.

[28] LI Chaoran,ZHANG Chao. A Study on the Authenticity Experience of B\&B Tourists-Taking Li-jiang Ancient City as an Example[J]. Tourism Overview,2016,(7):72-75.

[29] CHEN Xin. Study on the Shaping of Tourist Experience under the Principle of "Virtual Authenticity" [J]. Tourism Tribune, 2010,(11):13-19.

[30] Hawkins D I. Consumer Behavior [M]. Beijing:Powered By Site Engine,2003:220.

[31] Bettman J R. An Information Processing Theory of Consumer Choice [M]. Boston:Addison-Wesley Publishing Company, 1979:22-35.

[32] Baloglu S, McCleary K W. A model of destination image formation [J]. Annals of Tourism Research, 1999, 26(4):868-897.

[33] Baloglu S, McCleary K W. U.S. International pleasure traveler's images of four mediterranean destinations: A comparison of visitors and non-visitors [J]. Journal of Travel Research, 1999, 38(2):144-152.

[34] TAO Changjiang,LIU Shaolin. Analysis on the Urban Residents' Travel Intention Based on the Subjective Well-being — the Model of Dujiangyan [J]. Tourism Forum, 2012, 11(6):17-24.

[35] LIU Li. Screen-induced Tourism: Perceived Destination Image and Intention to Visit [J]. Tourism Tribune, 2013, 09(9):61-70.

[36] Goodrich J N. The relationship between preferences for and perceptions of vacation destinations:Application of a choice model[J]. Journal of Travel Research, 1978, 17(2):8-13.

[37] Chen C F,Tsai D. How destination image and evaluative factors affect behavioral intentions?[J]. Tourism Management,2007, 28(4):1115-1122.

[38] Wang C,Hsu M K. The relationships of destination image,satisfaction,and behavioral intentions:An integrated model[J]. Journal of Travel\&Tourism Marketing,2010,27(8):829-843.

[39] MA Ling. Tourist Attraction and Its Construction under the Perspective of Sociology [J]. Tourism Tribune,2009,(9):69-74.

[40] BAO Jigang,CHU Yifnag. Geography of Tourism[M]. Beijing:Higher Education Press,1999.

[41] LAI Bin,YANG Lijuan,LI Lingfeng. A Study on the Construction of Ethnic Minority Folk Custom Tourism Villages and Towns in the Perspective of Precision Poverty Alleviation-Based on the Investigation of Shangri-La Township in Daocheng Count[J]. Journal of southwest university for nationalities,2016,37(12):154-159. 
[42] HU Min. An Analysis of the Core Resources in the Management of Rural Lodgings[J]. Tourism Tribune,2007,(9):64-69.

[43] FU Xiaolan,ZHOU Hongwei. An Analysis of the Intention to Visit of Traditional Villages and Towns in Changsha City[J]. Co-Operative Economy\&Science,2016,08(15):27-29.

[44] LI Zhongbin, LIU Ali. Approaches to the integration of the construction of specialty industries and B\&B tourism in the Wuling Mountains: A case study at Lichuan Cit[J]. Journal of Yunnan Nationalities University,2016,33(06):108-114.

[45] ZHOU Yang,HE Junhong,RONG Hao. Satisfaction Evaluation of Tourist and Influence Factors Analysis in Rural Tourism[J]. Economic Management Journal, 2016,5(07):156-164.

[46] LI Jing,LIN Jing,LIU Jingbo. Development of the B\&B Industry in Taiwan [J]. The Guide of Science\&Education, 2015, (10):154-156.

[47] ZHOU Qiong. Analysis on The Development of Taiwan Homestay and Its Enlightenment [J]. Taiwan Agricultural Research, 2014,(01):13-17.

[48] YANG Xin,DUAN Yan. A Comparative Study of Bed and Breakfasts on Both Taiwan and Mainland [J]. Economic Research Guide, 2012,(34):187-209.

[49] CHEN Xiangming. The Ideas and Methods of Grounded theory[J]. Educational Research and Experiment, 1999, (04):58-63.

[50] Strauss A,Corbin J. Basics of Qualitative Research:Grounded Theory Procedures and Techniques[M]. New bury Park Sage, 1990:10-85.

[51] QIU Wei,BAI Changhong. Study on the Internalization of Tourism Brands Based on Grounded Theory:A Case of a Five-star Hotel[J]. Tourism Tribune, 2012,(10):46-52.

[52] FENG Jiechun. A Research on Structures and Functions of Online Public Sphere [M]. Beijing: Beijing University of Posts and Telecommunications, 2008:19-46.

[53] Bratman M. Intention, Plans, and Practical Reason [M]. HARVARD UNIVERSITY PRESS, 1987:241-254.

[54] Chen Xiangming. Qualitative research methods in social science [J]. Social Sciences in China, 1996, (6):93-102. 